\title{
Osmanlı Ahşap Kapı ve Pencere Kanatlarındaki Kompozisyonlar ve Altın Üçgenler
}

\section{Compositions and Golden Triangles in the Ottoman Wooden Door and Window Leaves}

\author{
Mustafa Bulut ${ }^{1}$ (D)
}

'Sorumlu yazar/Corresponding author: Mustafa Bulut (Dr.)

Istanbul, Türkiye

E-posta: blt8@hotmail.com

ORCID: 0000-0002-1891-5220

Başvuru/Submitted: 06.08.2019

Revizyon Talebi/Revision Requested:

08.05.2020

Son Revizyon/Last Revision Received:

13.05.2020

Kabul/Accepted: 14.05 .2020

Online Yayın/Published Online: 30.06 .2020

Atıf/Citation: Bulut, Mustafa, "Osmanlı Ahşap Kapı ve Pencere Kanatlarındaki Kompozisyonlar ve Altın Üçgenler". Sanat Tarihi Yıllığı - Journal of Art History 29 (2020), 45-61.

https://doi.org/10.26650/sty.2020.003

\section{ÖZ}

Ahşap malzeme gerek dayanıklılığı gerekse işlemeye elverişli olması nedeniyle mimari yapılarda yaygın olarak kullanılmıştır. Anadolu Selçuklu ve Osmanlı döneminden de çok sayıda kapı ve pencere kanadı, minber ve vaaz kürsüsü günümüze ulaşmıştır. Osmanlılarda klasik dönemden itibaren minberlerde mermer malzeme kullanımı görülse de kapı ve pencere kanatlarında her zaman ahşap malzeme tercih edilmiştir. Anadolu Selçukluların Konya Beyhekim Mescidi (13. yüzyıl son çeyreği) kapı kanatlarında ve bazı yapılardaki taş süslemelerde görülen beşgen-ongen kompozisyonun Beylikler döneminde kullanımı yaygınlaşmış, Osmanlı klasik döneminde ise kullanımı ahşap parçaların şekillerinin zenginleşmesiyle standart hale gelmiş ve kanatların çok büyük çoğunluğunda bu kompozisyon tercih edilmiştir. Araştırmada Osmanlı dönemi kapı ve pencere kanatlarının orta panolarında beşgen-ongen kompozisyonların tercih ediliş sebebi ve kökeni Anadolu Selçuklu dönemine kadar uzanan gelişim çizgisi üzerinde durulmuştur. Benzer şekilde bu kompozisyonların, kanatların alt panolarında ve bazı vaaz kürsülerinde de kullanımı incelenmiştir. Kapı ve pencere kanatlarında bu kompozisyonların büyük oranda $72^{\circ}$ eksende düzenlenmiş bir dikdörtgen içerisinde verildiği, vaaz kürsülerinde de $36^{\circ}$ eksendeki dikdörtgenlerin tercih edildiği görülmüştür. Bu iki açıya sahip üçgenler altın üçgen olarak ifade edilmektedir.

Anahtar kelimeler: Ahşap, Kapı kanadı, Pencere kanadı, Geometrik süsleme, Altın üçgenler

\section{ABSTRACT}

Wood materials have been used widely in architectural structures due to both durability and its convenience in processing. Many door and window leaves, minbar and preaching platforms from the Anatolian Seljuk and Ottoman periods have reached the present day. Although the use of marble material in the minbar was observed in the Ottomans since the classical period, wood materials have always been preferred in the leaves of the doors and windows. The use of pentagonal-decagonal composition; which is seen in the leaves of the doors of the Anatolian Seljuks Konya Beyhekim Mosque (The last quarter of the 13th century) and in stone decorations of some structures, became widespread in the 
Principalities period, and using these composition became common with the enrichment of the shapes of wooden pieces in the classical period of the Ottoman Empire and in most of the leaves, this composition was preferred. In the study, we will focus on the reasons and origin of the preference of pentagonal-decagonal compositions in the middle panels of the leaves of the doors and windows of the Ottoman period and on the development line extending to the Anatolian Seljuk period. Similarly, the use of these compositions in the lower panels of the leaves and in some preaching rostra has been studied. It was observed that these compositions were given within a rectangle arranged on $72^{\circ}$ axis on the door and window leaves, and rectangles on the $36^{\circ}$ axis were preferred in preaching rostra. Triangles with these two angles are referred to as golden triangles.

Keywords: Wood, Door leaf, Windows leaf, Geometric ornament, Golden triangles 
Osmanlı döneminde kullanılan ahşap malzeme üzerinde çok sayıda çalışma yapılmış ve bu çalışmalarda; kullanılan teknikler açıklanmış, dönemsel olarak değişen özellikler vurgulanmış ve yapılardaki ahşap eserlerin tanıtımları ve bazı genel değerlendirmeler yapılmışıır' ${ }^{1}$ Kapı kanatlarındaki süslemeler üzerinde de durulan bu çalışmaların bazılarında, Osmanlı klasik döneminden itibaren kapı ve pencere kanatlarında kullanılan geometrik süslemelerde çoğunlukla ongen kompozisyonların kullanıldığı tespiti yapılmıştır². Ancak bunun sebepleri üzerinde durulmamıştır. Anadolu Selçuklu döneminde örnekleri verilen, Beylikler döneminde sayıları artan beşgen-ongen kompozisyonlara sahip kapı kanatları, Osmanlı klasik döneminde ise neredeyse istisnasız olarak uygulanmıştır. Araştırmada Anadolu Selçuklu dönemi ile Osmanlı klasik dönemi aralığındaki zaman diliminde bu uygulamanın gelişimi ve nedenleri üzerinde durulacaktır ${ }^{3}$. Araştırma kapsamında üçü Anadolu Selçuklu dönemine ait toplam 67 kapı-pencere kanadı incelenmiştir.

Anadolu Selçuklular zamanından günümüze ulaşan ahşap eserler ağırlıklı olarak kapı kanatları ve minberlerdir. Kapı kanatları; geometrik, bitkisel, figürlü ve yazı süslemeleriyle dönemin özelliklerine göre yoğun olarak bezenmiştir. Anadolu Selçuklu ve Beylikler döneminde oyma, kakma, tarsi ve kafes tekniklerinin öne çıktığı görülür

Anadolu Selçuklu dönemi kapılarında kullanılan geometrik kompozisyonlar beşgen-ongen, altıgen, sekizgen ve onikigen açılarına sahiptir. Altıgen özellikli kompozisyonlar; Amasya Gök Medrese Camii (1266-67) ve Konya Sahip Ata Türbesi (1283) kapı kanatlarında görülmektedir. Sekizgen özellikli kompozisyonlar; Ankara Tavuslu Kapı (13. yüzyıl ilk yarısı), Akşehir Ferruh Şah Mescidi (1224), Akşehir Kızılca Mescit (13. yüzyıl ilk yarısı) ve Akşehir Seyyid Mahmut Hayrani Türbesi (13. yüzyıl üçüncü çeyreği) kapı kanatları üzerinde bulunmaktadır. Onikigen özellikli kompozisyonlar ise Kayseri Ulu Camii (1205-06), Karaman Figürlü Kapıs1 (13. yüzyıl başları) ve Ankara Kuyulu Camii (13. yüzyıl ilk yarısı) kapı kanatları üzerinde yer alır. Beşgen-ongen kompozisyonlara sahip kapılar; Ankara Aslanlı Kapı (13. yüzyıl başları),

1 Can Kerametli, “Osmanlı Devri Ağaç İşleri Tahta Oyma Sedef Bağ ve Fildişi Kakmalar”, Türk Etnografya Dergisi, S: IV, MEB Eski Eserler ve Müzeler Genel Müdürlüğü, Ankara, 1961, s. 5-13; Gönül Öney, “Anadolu Selçuklu ve Beylikler Devri Ahşap Teknikleri”, Sanat Tarihi Yıllığı, S: 3, Edebiyat Fakültesi Matbaası, İstanbul, 1970, s. 135-150; Yıldız Demiriz, "XIV. Yüzyılda Ağaç İşleri”, Yüzyıllar Boyunca Türk Sanatı (14. Yüzyıl), Haz: Oktay Aslanapa, MEB, Ankara, 1977, s. 61-71; Erdem Yücel, “Osmanlı Ağaç İşçiliği”, Kültür ve Sanat, İstanbul, 1977, s. 58-71; Ayla Ersoy, XV. Yüzyıl Osmanlı Ağaç İşçiliği, Marmara Üniversitesi Yayınları, İstanbul, 1993; Rüstem Bozer, "Sinan Eserlerinde Ahşap İşçiliği”, VI. Vakıf Haftası, Türk Vakıf Medeniyeti Çerçevesinde “Mimar Sinan ve Dönemi” Sempozyumu İstanbul, 1989, s. 327-346; Rüstem Bozer, “Ahşap Sanatı”, Anadolu Selçukluları ve Beylikler Dönemi Uygarlığı 2, Kültür ve Turizm Bakanlığı, Ankara, 2006, s. 533-541; Örcün Barışta, Osmanlı İmparatorluğu Dönemi İstanbul Camii ve Türbelerinde Ağaç İşleri, AKM, Ankara, 2009.

2 Rüstem Bozer, a.g.e., 1989, s. 330; A. Mehmet Avunduk, Mimar Sinan'ın İstanbul'daki Camilerinde Ağaç Sanatı, İ.Ü., Sosyal Bilimler Enstitüsü Yayımlanmamış Doktora Tezi, İstanbul, 1996, s. 73; İmran Döngel, İstanbul'daki Mimar Sinan Eseri Cami Kapılarının İncelenmesi, G.Ü., Fen Bilimleri Enstitüsü Yayınlanmamış Yüksek Lisans Tezi, Ankara, 2013, s. 42; Cevdet Sögütlü, vd., "İstanbul'da Bulunan Mimar Sinan Eseri Cami Ahşap Kapı ve Pencere İç Kepenklerinin Malzeme, Boyut, Süsleme ve Yapım Tekniği Açısından İncelenmesi”, Politeknik Dergisi, C: 17, S: 2, Ankara, 2014, s. 52.

3 Bu konudaki fikirlerini benimle paylaşan Mustafa Sancak'a çok teşekkür ederim.

4 Rüstem Bozer, a.g.e., 2006, s. 533. 
Sahip Ata Camii Kapısı (1258), Konya Beyhekim Mescidi’ne (13. yüzyıl son çeyreği) ait üç kapı kanadı ve Ankara Baklacı Baba Mescidi (1297-98) kapı kanatlarıdır.

Kapı kanatlarının panolara bölünmesi uygulamasına, farklı büyüklük ve farklı sayılarda olması koşuluyla Anadolu Selçuklu döneminde de rastlanılmaktadır. Geometrik kompozisyonlar, bazı kapı kanatlarının ortalarındaki madalyonlarda düzenlenmiş, bazı kapı kanatlarının da yüzeylerinde oluşturulan farklı büyüklükteki panolara işlenmiştir.

Anadolu Selçuklu dönemi kapı kanatlarındaki geometrik bezemelerin büyük bölümü kompozisyon çoğaltılma sınırları dikkate alınarak panolara işlenmiştir. Ankara Kuyulu Camii, Amasya Gök Medrese Camii ve Ankara Baklacı Baba Mescidi kapı kanatlarında ise bu uygulamaya dikkat edilmemiştir. Ankara Kuyulu Camii kapı kanatlarının biri diğerinden biraz dar yapıldığından dar olan kanada kompozisyon tam olarak işlenememiştir. Amasya Gök Medrese Camii kapı kanatlarında kompozisyon düşeyde sınırlarından verilmişken, yatayda buna dikkat edilmemiştir. Ankara Baklacı Baba Mescidi kapı kanadındaki geometrik kompozisyonda ise panonun sol ve üst tarafı kompozisyon çoğaltılma sınırlarından verilmişken sağ ve alt tarafında bu duruma dikkat edilmemiştir ${ }^{6}$. Panolarındaki geometrik kompozisyonlar açısından kompozisyon çoğaltılma sınırlarına dikkat edilen hiçbir Anadolu Selçuklu kapı kanadında tek raport kullanımı uygulamasına gidilmemiştir. Mevlana Dergâhı'na ait ve muhtemelen bir parçası eksik olan pencere kanadında (F. 1) ve Konya Beyhekim Mescidi'ne ait kapı kanadında (Ç. 1) kompozisyon yarım raport olarak verilirken, Konya Beyhekim Mescidi’ne ait bir diğer kap1 kanadında ise kompozisyon çeyrek raport olarak verilmiştir (F. 2). Bu üç kapı kanadı dışındaki bütün kapı kanatlarında kompozisyonlar panolara farklı raport sayılarıyla işlenmişlerdir.
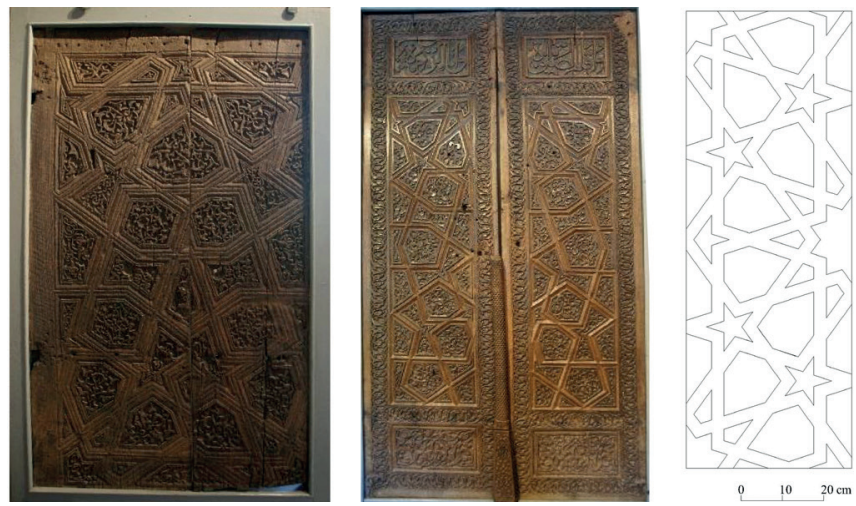

F. 1: Konya İnceminare Taş ve Ahşap Eserleri Müzesi’nde sergilenen Konya Mevlana Dergâhı'na ait pencere kanadı

F. 2: Konya Beyhekim Mescidi (13. yüzyıl son çeyreği) kapı kanadı Ç. 1: Konya Beyhekim Mescidi ikinci kapı kanadı (M. Bulut)

5 Selçuklu dönemine ait kapı kanatlarının tarihleri Rüstem Bozer, 15. Yüzyılın Ortasına Kadar Anadolu Türk Sanatında Ahşap Kapılar, Ankara Üniversitesi Sosyal Bilimler Enstitüsü, Yayınlanmamış Doktora Tezi, Ankara, 1992'den alınmıştır.

6 Rüstem Bozer, a.g.e., 1992, s. 146'da bu durum sanatçının simetriden uzaklaşma isteğine bağlanmıştır. 
Anadolu Selçuklu dönemine ait kapı kanatları üzerinde yapılan incelemede kapı kanatlarının ölçülerinin 0,54x155 ile 0,91×2,90 m. arasında değiştiği görülmektedir ${ }^{7}$. Bu kanatların uzun kenarlarının kısa kenarlarına oranları da 2,82 ile 3,82 arasında değişmekle birlikte ortalaması 3,17 oranına tekabül etmektedir. Osmanlı dönemine ait kapı kanatları üzerinde yapılan incelemede kapı kanatlarının ölçülerinin 0,78x2,64 ile 1,40x4,90 m. arasında değiştiği görülmektedir ${ }^{8}$. Bu kanatların uzun kenarlarının kısa kenarlarına oranları da 3,21 ile 3,85 arasında değişmekte, ortalaması da 3,40 oranına tekabül etmektedir. Rakamlardan da görülebileceği üzere Osmanlı döneminde Anadolu Selçuklu dönemine göre kapı kanatlarının boyutları büyümesine rağmen kapı kenarlarının birbirlerine olan oranlarındaki değişiklik oldukça sınırlı kalmıştır.

Osmanlı Devleti'nin ilk dönemlerinde de Anadolu Selçuklu döneminde olduğu gibi beşgenongen, altıgen, sekizgen ve onikigen kompozisyonlar tercih edilmiştir. Farklı çokgenlerle yapılan bu kanatlarda da yine birden fazla raport tercih edilmiştir. Ancak bu tasarımlardan klasik döneme kalacak olanlar, beşgen-ongen açılara sahip tek raportun işlendiği kapı kanatları olacaktır.

Osmanlı döneminde Bursa Yeşil Cami (1414-19) pencere kanatları (Ç. 2), merkezinde on köşeli yıldız bulunan ve tek kompozisyona sahip ilk kapı kanadıdır. Ancak köşelerde çeyrek ongen kompozisyonlar kullanılmadan kompozisyon tamamlanmıştır. Bu kapı kanadındaki çizgilerin iki yivle üç eşit parçaya bölünecek şekilde düzenlenmesi ve ortadaki ongen kompozisyonun, yivlerin ayırdığı bölümlerden biriyle oluşturulması, Selçuklu döneminde sadece Konya Beyhekim Mescidi mihrap nişinde bulunan (F.3) ve aynı şekilde tasarlanan ongen kompozisyonu hatırlatması bakımından önemlidir. Benzer uygulamalar Osmanlı döneminde Bursa Cem Sultan Türbesi (1474-79), Fatih Tabhanesi ${ }^{9}$ (1463-70) kapısı ve Atik Valide Sultan Camii (1570-79) pencere kanatlarında (Ç. 3) da tekrarlanmıştır. Bu kompozisyon, merkezdeki ongen kompozisyonun yaylarla oluşturulan farklılığı dışında Bursa Muradiye Camii’nde (1425-26) de kullanılmıştır.

Osmanlı döneminde Edirne Muradiye Camii ve Amasya Beyazıt Paşa Camii kapı kanatlarında (F. 4) köşelere yakın bölümlere yarım on köşeli yıldızlar oluşturulmuş, devamında ise yarım çokgenlerle tasarım tamamlanmıştır. Bursa Yeşil Türbe kapı kanadında ise çeyrek on köşeli yıldızlar köşelere düzenlenmesine rağmen geometrik şekillerin sayısının azlığı dikkat çekmektedir. Erken tarihli olan bu yapılardaki kanatların deneme aşaması örnekleri oldukları söylenebilir. Edirne Üç Şerefeli Cami (1443-47) avlu ve Edirne Muradiye Camii (1436) kapı kanatlarında kompozisyon çoğaltma sınırlarının dikkate alınmadığı görülmektedir. Bu durum az sayıdaki yapıda karşılaşılan bir uygulama olması nedeniyle tasarım hatası olarak kabul edilebilir. Bu yapılar dışındaki kapı kanatlarının neredeyse tamamında ise köşeleri çeyrek on köşeli yıldızlarla nihayetlenen ve merkezinde bir on köşeli yıldız bulunan kompozisyonlar çok sayıdaki geometrik şekillerle raport olarak verilmiştir.

7 Rüstem Bozer, a.g.e., 1992, s. 46-147.

8 İmran Döngel, a.g.e., 2013, s. 35; Cevdet Söğütlü, a.g.e., 2014, s. 52.

9 H. Baki Kunter-A. Sami Ülgen, "Fatih Camii”, Vakıflar Dergisi, S. 1, Ankara, 1938. Bahse konu kapı kanad1 Ayla Ersoy , a.g.e., 1993, s. 45’te Fatih Karadeniz Medresesi kapı kanadı olarak geçmektedir. 

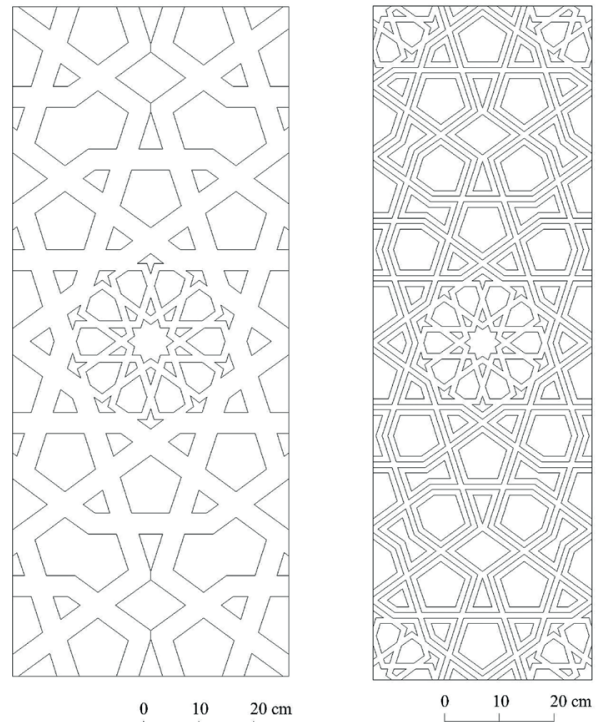

Ç. 2: Bursa Yeşil Camii (1414-19) pencere kanatlarında kullanılan kompozisyon (M. Bulut) Ç. 3: Atik Valide Sultan Camii (1570-79) pencere kanatlarında kullanılan kompozisyon (M. Bulut)

Anadolu Selçuklu sanatında kullanılan bir ongen kompozisyon (F. 5) ise Osmanlı döneminde kapı ve pencere kanatlarında kullanılan ongen kompozisyonların ilham kaynağı olmuştur. $\mathrm{Bu}$ kompozisyon dönem yapılarından; Hunat Hatun Medresesi (1238), Sahip Ata Camii (1258), Ahlat Hüseyin Timur Türbesi (1280), Mevlana Türbesi ahşap sandukası ve İnceminare Taş ve Ahşap Eserleri Müzesi’nde sergilenen Mevlana Dergâhı pencere kanadında kullanılmıştır ${ }^{10}$.

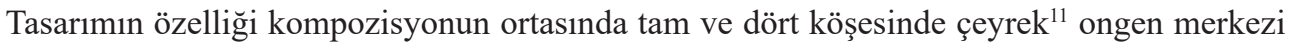
kompozisyonun olması ve kompozisyonun kısa kenarının uzun kenarına oranının yaklaşık 1/3'ün üzerinde, yani uzun bir dikdörtgen olmasıdır. Anadolu Selçuklu yapılarında kullanılan bu kompozisyon $72^{\circ}$ eksende düzenlenmiş bir dikdörtgen içerisine kurulmuştur. 72 derecede düzenlenen dikdörtgenin yaklaşık 1/3 olan oranının tam rakamsal karşılığ 1 ise 3,08 olmaktadır.

Anadolu Selçuklu yapılarında görülen kompozisyonun Osmanlı döneminde tek kompozisyon halinde ve ahşap üzerine işlendiği ilk örnek Edirne Üç Şerefeli Camii (1443-47) pencere kanatlarıdır. Bu kompozisyon daha sonra Amasya Beyazıt Camii (1486), Hürrem Sultan Türbesi (1558) ve Rüstem Paşa Camii (1561) pencere kanatlarında da kullanılmıştır.

10 Mustafa Bulut, Selçuklu Çizgileri Anadolu Selçuklu Geometrik Kompozisyonları, Inkılab Basım Yayım, İstanbul, 2020, s. 132.

11 Metin Arık,-Mustafa Sancak, Pentapleks Kaplamalar, Tübitak, 2006, s. 103. Ayrıca s. 98'de Konya Karatay Medresesi ana eyvan tonozundaki beşgen-ongen kompozisyonun Osmanlı dönemi ahşap kapılarına örnek olduğu belirtilmiştir. Ancak kompozisyon $36^{\circ}$ eksende tamamlanmıştır. 
Bursa Yeşil Camii kapı kanadındaki kompozisyonun, köşeleri çeyrek ongen kompozisyonla nihayetlenen şekli Fatih Tabhanesi kapı kanadında tekrarlanmıştır. Bursa Cem Sultan Türbesi kapı kanadı süslemesi de benzer yönüyle dikkat çeker. Bununla birlikte bu kompozisyonlardaki geometrik şekillerin, Osmanlı klasik dönemindeki ölçüleri düşünüldüğünde hala büyük oldukları fark edilmektedir.

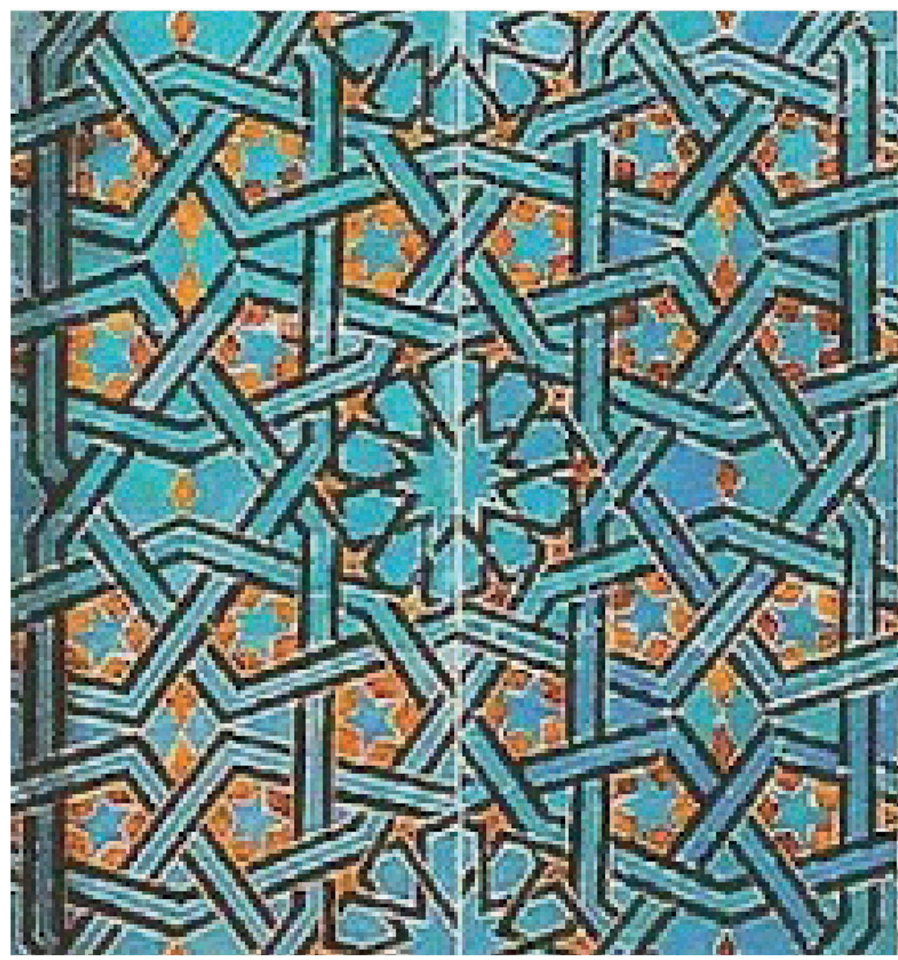

F. 3: Konya Beyhekim Mescidi Mihrap nişi çini süslemesi (Rüçhan Arık-Oluş Arık, 2007, s. 139) 

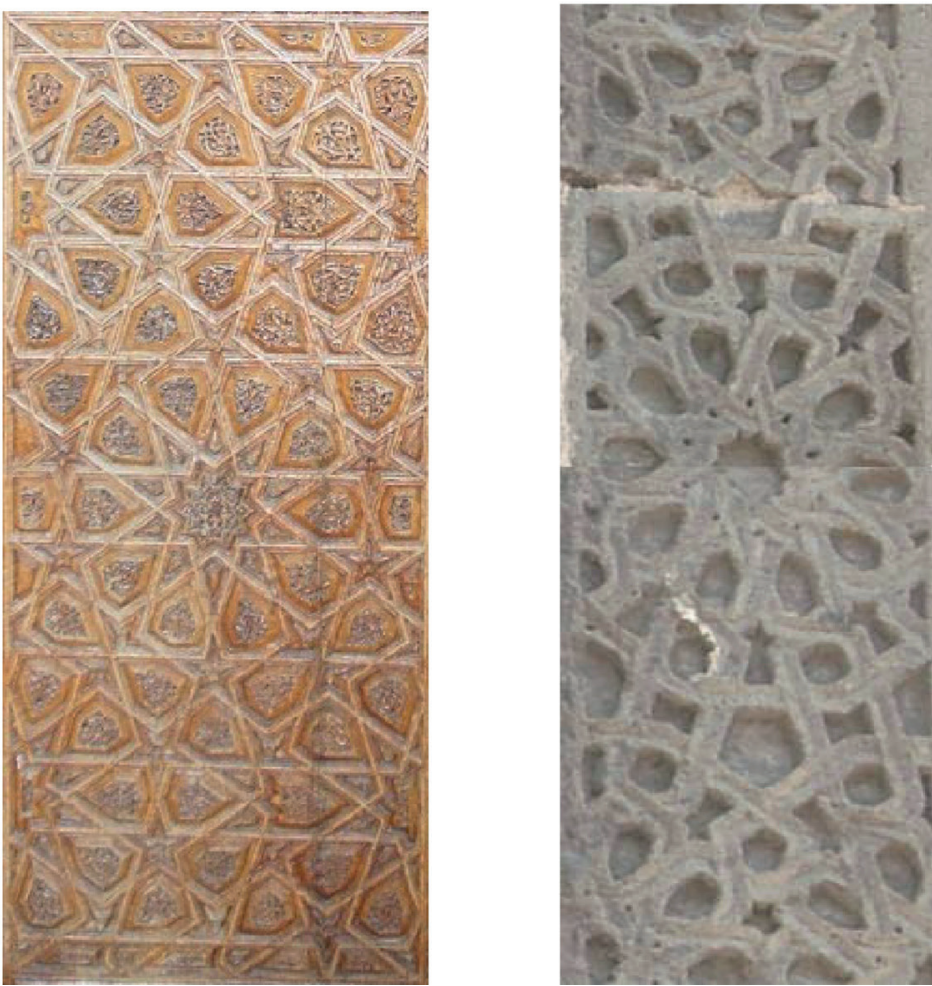

F. 4: Amasya Beyazıt Paşa Camii kapı kanadı

F. 5: Hunat Hatun Medresesi taçkapı bordürü

Osmanlı klasik dönemindeki kapı ve pencere kanatları orta pano süslemelerinin; merkezde on köşeli yıldız, köşelerde bu kompozisyonun çeyreği ve arada kalan bölümlerin ongen sistemi içerisinde elde edilen çok sayıdaki geometrik şekille bezenmesi şeklinde bir tasarımı bulunmaktadır (Ç. 4). Bu tasarımla birlikte geometrik şekillerin küçülmesi ve sayısının artması şeklindeki uygulama ilk olarak Tokat Hatuniye Camii (1484) kapı kanatlarındaki kompozisyonlarda görülmektedir. Bursa Yeşil Cami kapı kanadında 93 olan geometrik şekillerin sayısı Tokat Hatuniye Camii kapı kanatlarında 239'a yükselmiştir. Bu sayı Edirne Selimiye Camii (1575) kapı kanatlarında 800 civarındayken, Süleymaniye Camii (1557) kapı kanadında (Ç. 5) 1000'in üzerindedir.

Osmanlı dönemi kapı kanatlarındaki beşgen-ongen kompozisyonların büyük bir kısmı beşgenler üzerinden hareket edilerek oluşturulmuştur. Bununla birlikte diğer geometrik şekillerin de rahatlıkla ongen sistemi içerisinden çıkarılabileceği görülmektedir (Ç. 4).

Araştırmada, Anadolu Selçuklu ve Osmanlı dönemine ait yapılardaki 67 kapı ve pencere kanadı incelenmiştir. Bu kanatlardan kitabeli olanların yanında kitabesi olmayan, restorasyona tabi tutulan ve daha geç tarihlerde tamamı yeniden yapılan kanatların olduğu görülebilir. 
Kanatlarda kullanılan beşgen-ongen kompozisyonların kullanım amacının araştırılması sebebiyle kanatların özgün olup olmamasının araştırmanın sonucuna bir etkisi bulunmamaktadır. Klasik döneme ait bir yapıda daha geç tarihli bir kanadın klasik dönemdeki haliyle kullanımının tercih edilmesi aynı sonuca hizmet ettiğinden kapıların özgünlüğü konusunda ayrıca durulmamıştır. Bununla birlikte günümüzde yapılan bazı camilerin kapı kanatlarında da beşgen-ongen kompozisyonların tercih edildiği görülebilmektedir.

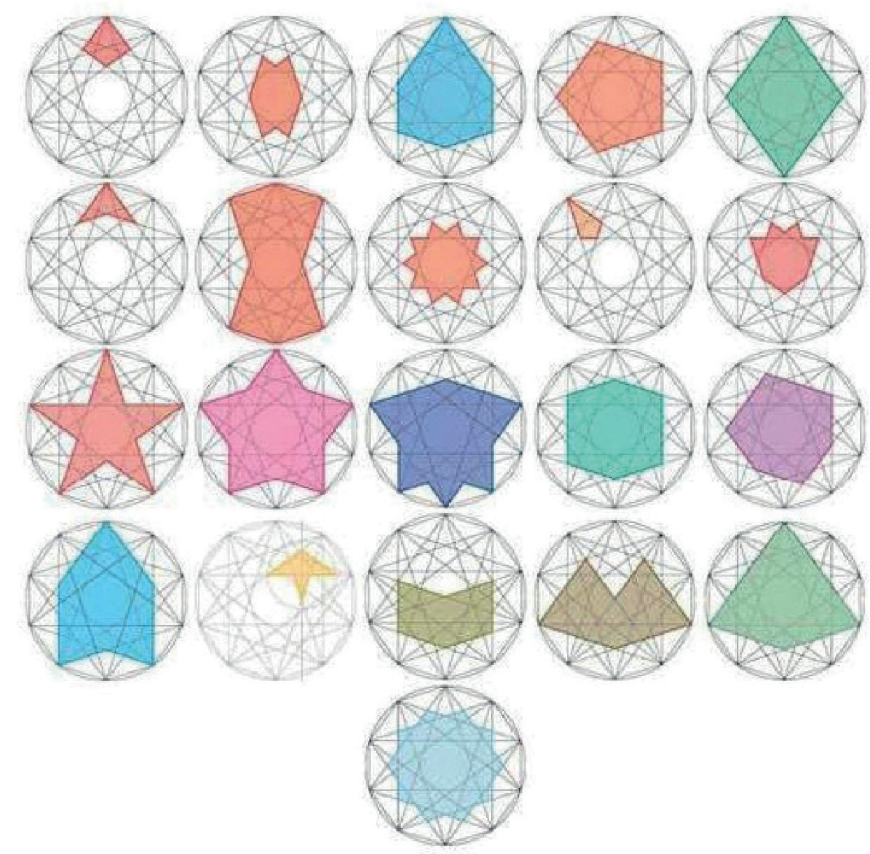

Ç. 4: Kapı kanatlarında kullanılan geometrik şekillerin ongen sistemi içerisinden çıkarılması (Serkan Baykuşoğlu, 2009, s. 34)

Anadolu Selçuklu geometrik kompozisyonlarından altıgen kompozisyonların raportları, altıgenlerle yapılabildiği gibi, altıgenin karşılıklı iki paralel kenarında oluşturulan ve 1,73 oranına sahip dikdörtgen içerisinde de yapılabilmektedir. Kare ve sekizgen açılara sahip kompozisyonların neredeyse tamamının raportları karelerden oluşmaktadır. Onikigen açılara sahip kompozisyonların da raportları kare, altıgen veya dikdörtgen şeklinde olabilmektedir. Bu kompozisyonlardaki dikdörtgen de yine 1,73 oranına sahiptir. Beşgen-ongen kompozisyonların tamamının raportları dikdörtgendir. Özellikle Anadolu Selçuklu dönemi Kayseri yapıları ve istisna olarak da Kırşehir Alaaddin Camii (1246-47) taçkapısı süslemeleri büyük oranda beşgen-ongen kompozisyonlara sahiptir. Bu kompozisyonların, merkez etrafında şekillenmeyen, beşgenlerin 
farklı eksenlerde sıralanarak oluşturulduğu kompozisyonlar oldukları söylenebilir. Osmanlı döneminde kapı ve pencere kanatlarının, bu beşgen kompozisyonların merkezi kompozisyon etrafında şekillenen haliyle tekrarlandığı görülmektedir. Osmanlı Klasik döneminde kapı kanatlarının ortalama 3,40 oranına sahip olmaları ve bu dikdörtgen kanadın üç panoya bölünmesi neticesinde orta bölümde, oranı yaklaşık 3 olan bir dikdörtgen meydana getirilmiştir. $\mathrm{Bu}$ orana sahip dikdörtgen içerisine tekrar yapmadan kompozisyonu düzenlemek beşgen-ongen kompozisyonların kullanılmasıyla mümkündür. Osmanlı dönemine ait incelenen 64 kap1 ve pencere kanadının 36'sı, 72 ${ }^{\circ}$ açıyla oluşturulmuş bir dikdörtgen içerisine tasarlanmıştır (Ç. 7). Bu açı Süleymaniye Camii kapı kanadındaki panoda $69^{\circ}$ dereceye kadar düşürülmüşken (2,6 oranındaki dikdörtgen), Yavuz Sultan Selim Camii avlusundaki Şehzadeler Türbesi ve Hürrem Sultan Türbesi kapı kanadında $78^{\circ}$ dereceye kadar (4,8 oranındaki dikdörtgen) yükseltilmiştir.
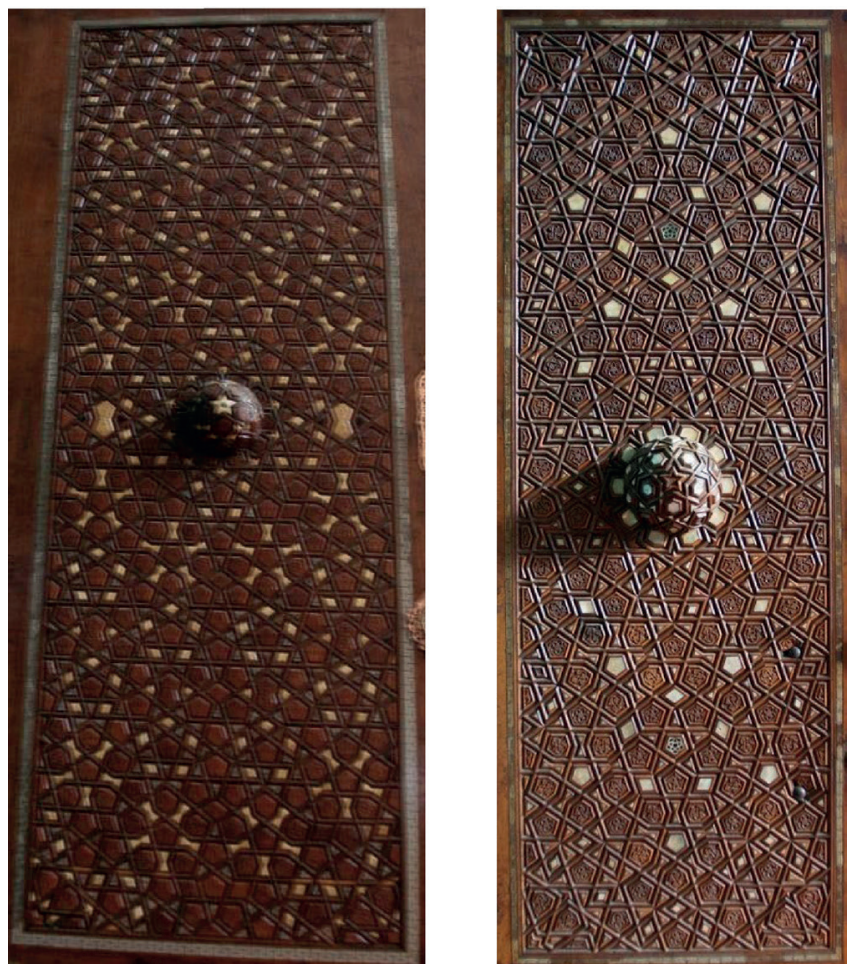

F. 6: Süleymaniye Camii (1557) kuzey kapı kanadı orta pano geometrik süslemesi

F. 7: Rüstem Paşa Camii (1561) kapı kanadı orta pano geometrik süslemesi 

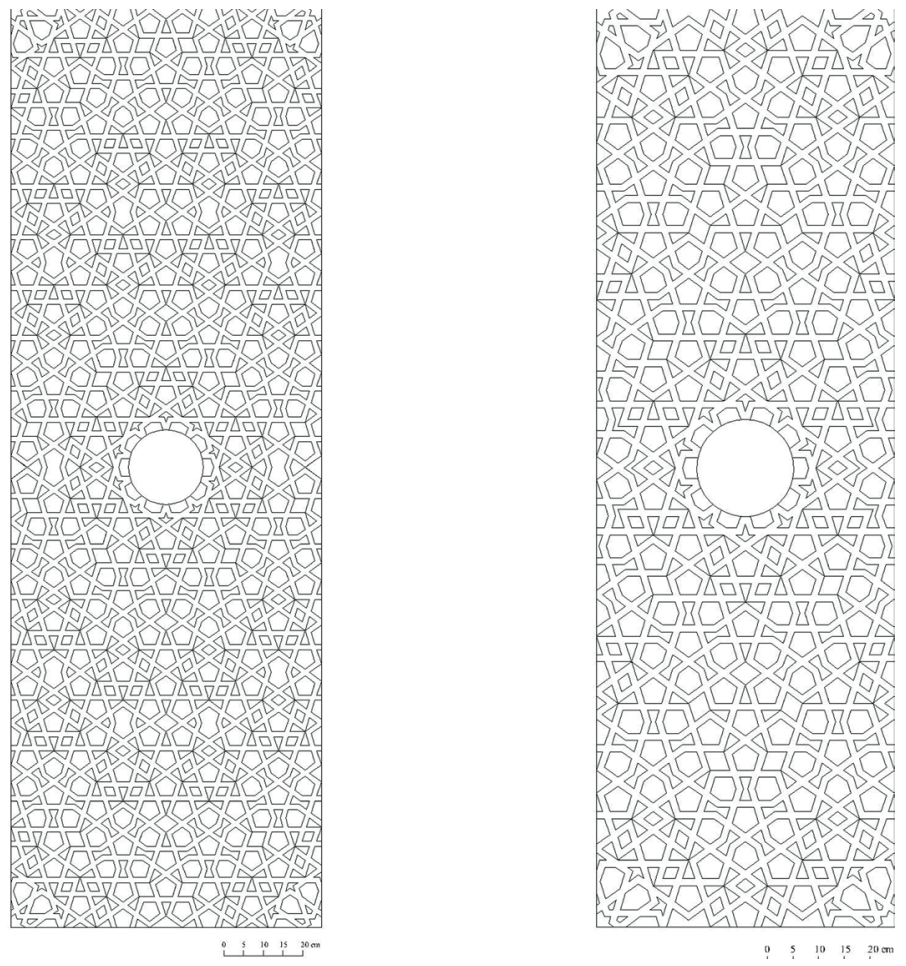

Ç. 5: Süleymaniye Camii (1557) kuzey kapı kanadı (M. Bulut) Ç. 6: Rüstem Paşa Camii (1561) kapı kanadı (M. Bulut) 

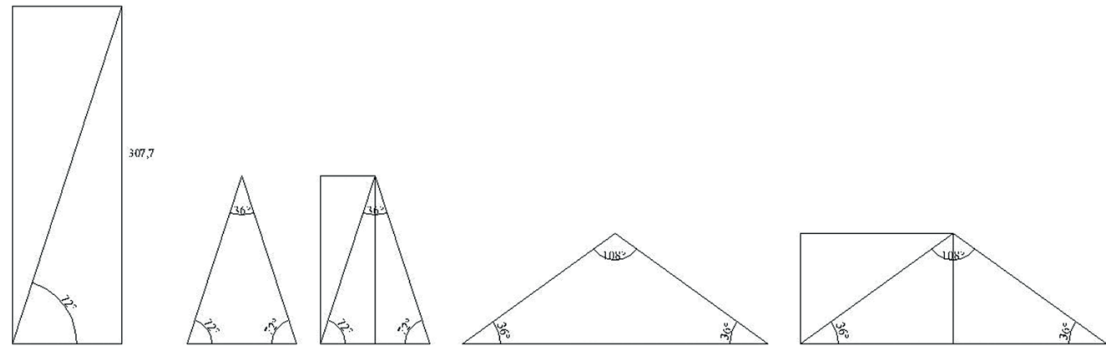

Ç. 7: Klasik Osmanlı dönemi kapı ve pencere kanatlarının geometrik kompozisyonların düzenlendiği $72^{\circ}$ açıya sahip dikdörtgen ve oranları

Ç. 8: $36^{\circ}$ tepe açısına sahip altın üçgen

Ç. 9: $36^{\circ}$ tepe açısına sahip altın üçgenin $36^{\circ}$ ve $72^{\circ}$ açılarda oluşturulan dikdörtgen Osmanlı dönemi kapı kanatlarındaki orta panoların büyük kısmının oranını vermektedir

Ç. 10: $108^{\circ}$ tepe açısına sahip altın üçgen

Ç. 11: $108^{\circ}$ tepe açısına sahip altın üçgenin $36^{\circ}$ ve $108^{\circ}$ açılarda oluşturulan dikdörtgen Osmanlı dönemi kapı kanatlarındaki alt panoların büyük kısmının oranını vermektedir

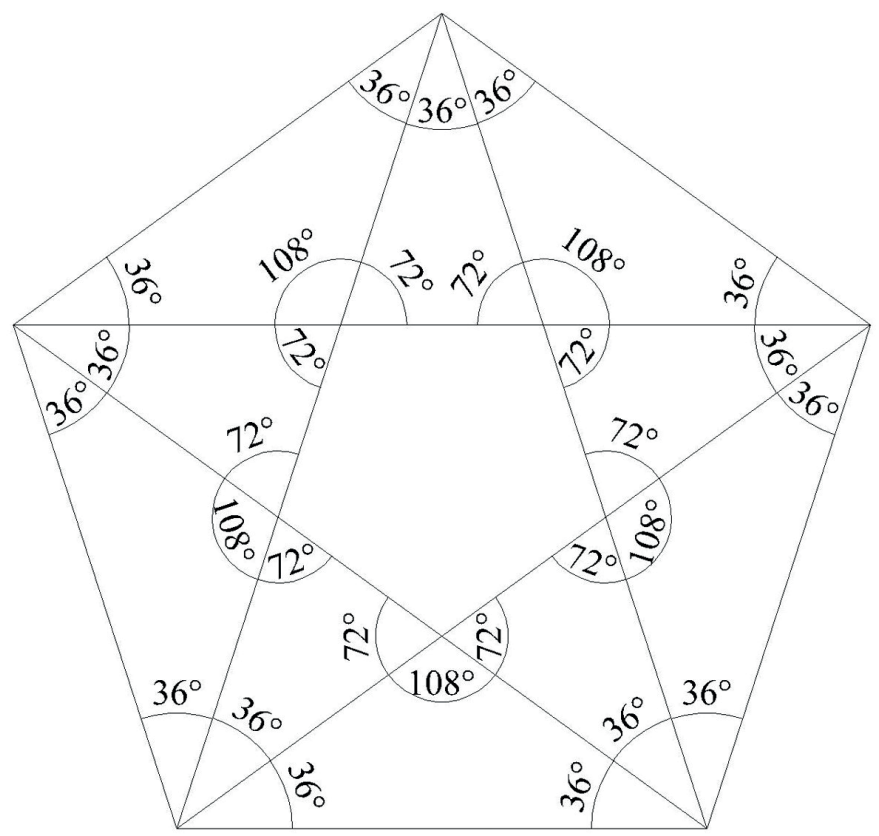

Ç. 12: Düzgün beşgen içerisindeki altın üçgenler 

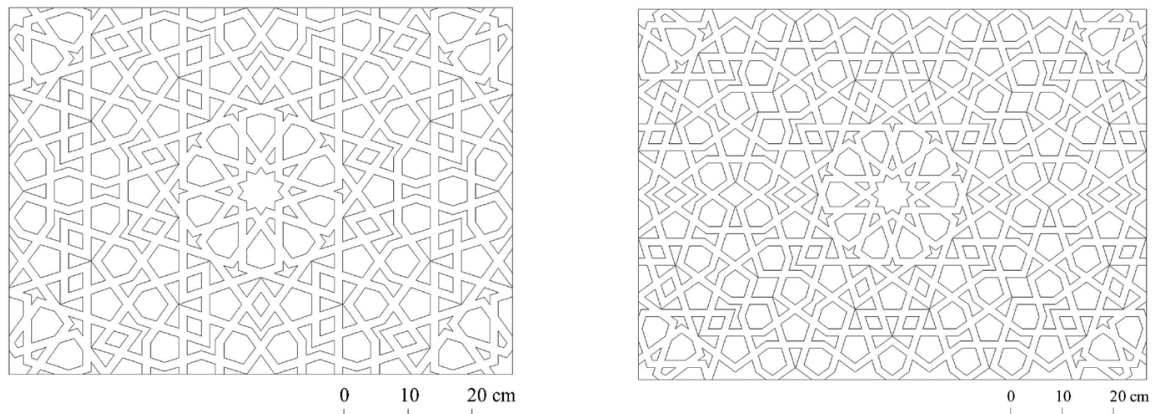

Ç. 13: Süleymaniye Camii (1557) kapı kanadı alt panosundaki $36^{\circ}$ açıyla oluşturulan beşgen-ongen süsleme (M. Bulut)

Ç. 14: Süleymaniye Camii (1557) vaaz kürsüsündeki $36^{\circ}$ açıyla oluşturulan beşgen-ongen kompozisyon (M. Bulut)
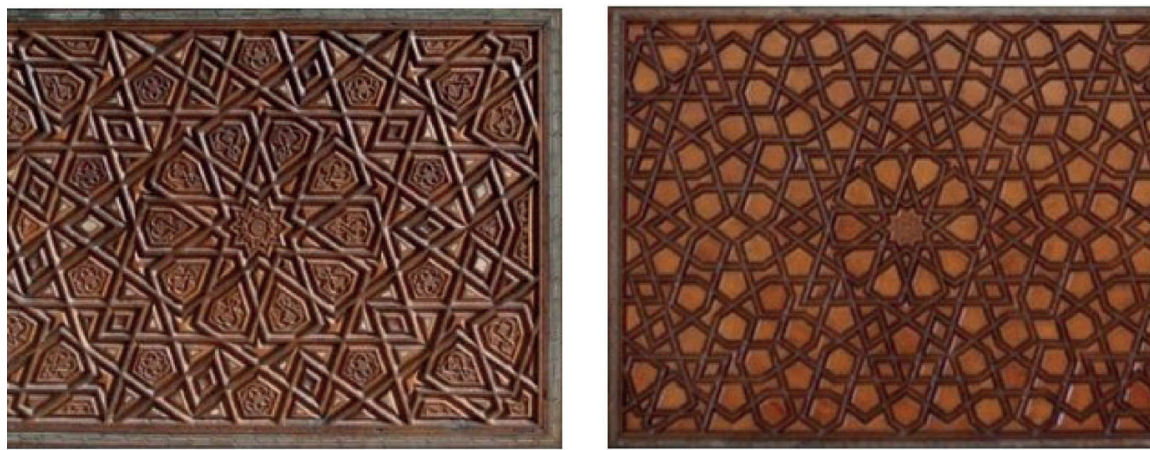

F. 8: Rüstem Paşa Camii (1561) kapı kanadı alt pano geometrik süslemesi F. 9: Süleymaniye Camii (1557) vaaz kürsüsü yan pano geometrik süslemesi

Geometride $36^{\circ}-72^{\circ}-72^{\circ}$ (Ç. 8) ve $108^{\circ}-36^{\circ}-36^{\circ}$ (Ç. 10) açıya sahip olan üçgenler altın üçgen olarak ifade edilmektedir ${ }^{12}$. Osmanlı dönemine ait incelenen 64 kapı kanadının 36'sında kullanılan $72^{\circ}$ açıya sahip olan dikdörtgen, tepe açısı $36^{\circ}$ olan altın üçgenin iki köşesinin birleşimiyle elde edilmektedir (Ç.9). Diğer kapı kanatlarının açıları da 72 dereceye çok yakın olmakla birlikte Süleymaniye Camii batı, Şehzadeler Türbesi ve Hürrem Sultan Türbesi kapı kanadı gibi az sayıda örnekte bu oran farklıdır.

Beşgen kompozisyonların $18^{\circ}$ ve katlarındaki eksenleri, aynı zamanda Osmanlı dönemi kapı ve pencere kanatlarının en alt panolarında kullanılan $36^{\circ}$ açıyla oluşturulmuş dikdörtgenleri de kapsamaktadır (Ç. 13). Yavuz Sultan Selim Camii, Üsküdar Mihrimah Sultan Camii, Kadırga Sokullu Mehmet Paşa Camii ve II. Selim Türbesi kapı kanatlarındaki alt panolar incelenen kapılardan $36^{\circ}$ açıya sahip olmayan kapılar arasındadır. Bunlar dışındaki kapı kanatlarında beşgen-ongen kompozisyona sahip alt panoların tamam $16^{\circ}$ açıyla tasarlanmışlardır. Osmanlı

12 Metin Arık,-Mustafa Sancak, a.g.e., 2006, s. 168. 
döneminde ahşap malzemeyle yapılan ve beşgen-ongen kompozisyonlara sahip olan Süleymaniye Camii (Ç. 14), Rüstem Paşa Camii, Kadırga Sokullu Mehmet Paşa Camii ve Sultan Ahmed Camii vaaz kürsülerinin de benzer şekilde $36^{\circ}$ açıyla tasarlandıkları görülmektedir. İstanbul Beyazıt Camii vaaz kürsüsünde ise kompozisyon $18^{\circ}$ açının bir başka katı olan $54^{\circ}$ açı ile tasarlamıştır. $36^{\circ}$ eksendeki tasarımın en önemli örneği 1,95x2,70 m. ölçüleriyle Anadolu Selçuklu dönemindeki en büyük ölçülere sahip kompozisyon olan Konya Karatay Medresesi ana eyvan tonoz yüzeyindeki çini süslemedir. Tonoz yüzeyindeki büyük alan, küçük ölçekli raportlarla boğulmak yerine, daha büyük ölçekli raportla akıcı hale getirilmiştir. Aynı zamanda $36^{\circ}$ açıya sahip olan dikdörtgen, tepe açısı $108^{\circ}$ olan altın üçgenin iki köşesinin birleşimiyle elde edilmektedir (Ç. 11). Osmanlı dönemine ait bu uygulamalar ölçülerin değilse de oranların standart hale getirildiğini göstermesi açısından önemlidir.

Bununla birlikte merkezdeki tam ve köşelerdeki çeyrek on köşeli yıldızlar yerine panoların diğer bölümlerinde olduğu gibi beşgen özellikli kompozisyonların veya beş köşeli yıldızın neden kullanılmadığı sorusu akla gelebilir. Panoların diğer bölümlerinde olduğu gibi merkezde ve köşelerde beşgen özellikli kompozisyonların kullanımı; Kayseri bölgesi Anadolu Selçuklu yapılarında olduğu gibi merkezi olmayan, sıralı bir kompozisyon meydana getirirdi ${ }^{13}$ (Konya Sahip Ata Camii kapı kanatlarında kompozisyon bu şekilde yapılmış ve Anadolu Selçuklu ahşap sanatında bir daha tekrarlanmamıştır). Bu da yatay veya düşeyde simetri ekseninin bozulmasına neden olurdu. Merkezde ve köşelerde beşgen özellikli diğer şekillerin ve beş köşeli yıldızın kullanımı da aynı şekilde yatay veya düşeyde simetri ekseninin bozulmasına neden olmaktadır (Ç. 16). Aynı zamanda kompozisyonun pano üzerinde raport haliyle verilememe durumu ortaya çıkmaktadır. Dolayısıyla simetri eksenini bozmadan merkezi bir kompozisyon elde etmek beşgen özellikli süslemelerde çoğunlukla kullanılan ongen kompozisyonların ve on köşeli yıldızın kullanılmasına bağlıdır ve örneklere de bu şekilde yansıtılmıştır.
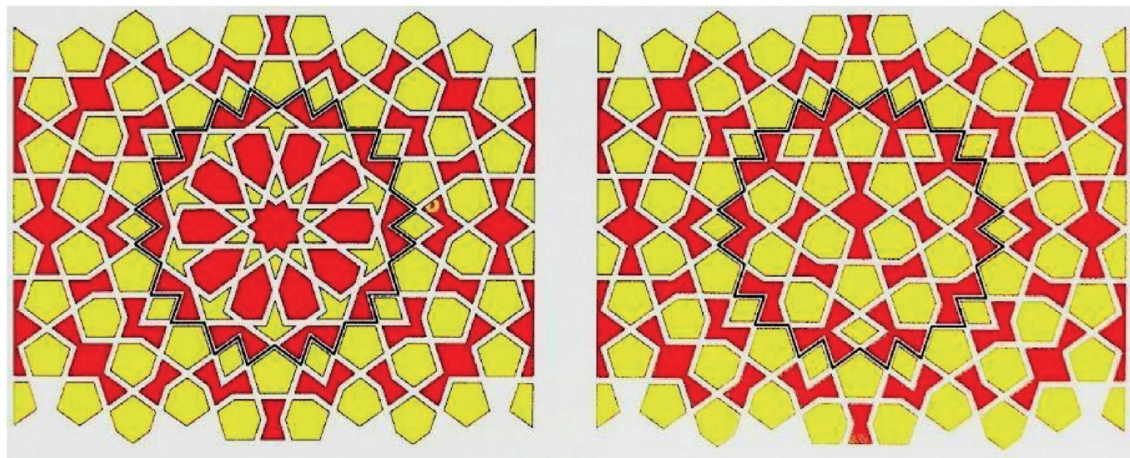

Ç. 15-16: On köşeli yıldıza sahip merkezi kompozisyonun sıralı bir kompozisyona dönüştürülmesi (Metin Arık,-Mustafa Sancak, 2006, s. 116, Şekil 3.26) 
Anadolu Selçuklu dönemi kapı kanatlarında, oldukça büyük olan geometrik şekillerin 30 civarında olan sayısı, Beylikler döneminde 300'e, Klasik Osmanlı döneminde de 1000'lere ulaşarak çok daha büyük ve ayrıntılı kompozisyonlar yapılmıştır. Osmanlı döneminde orta pano ölçüleri yaklaşık 1/3 oranındadır ve bu bölümlere tek raport halinde bir kompozisyonun işlenmesi beşgen-ongen kompozisyonlarla mümkün olmuştur. Tepe açısı $36^{\circ}$ olan altın üçgenin, araştırma dâhilindeki Osmanlı dönemi ahşap kapı ve pencere kanatlarının büyük bölümünde net olarak uygulandığı görülmektedir (Ç.7). Diğer kanatlarda ise bu açıya oldukça yakın orana sahip dikdörtgenler içerisine yapıldıkları görülür. Alt panolarda ve bazı vaaz kürsüsü panolarında ise $36^{\circ}$ eksende yapılan dikdörtgenler tercih edilmiştir. Bununla birlikte kompozisyonların yatay ve düşeyde simetrik eksenlerinin alınabilmesi ve sonsuz karakterli olabilmeleri için de tamamen beşgenlerden oluşturulmamış, merkeze tam köşelere de çeyrek olmak kaydıyla on köşeli yıldızlar düzenlenmiştir.

Araştırma kapsamında Konya Beyhekim Mescidi (2 kapı kanadı), Bursa Yeşil Türbe, Bursa Cem Sultan Türbesi, Fatih Tabhanesi, Tokat Hatuniye Camii, Edirne II. Beyazıt Camii, İstanbul II. Beyazıt Camii, Yavuz Sultan Selim Camii, Yavuz Sultan Selim Türbesi, Şehzadeler Türbesi, Şehzade Mehmet Camii, Şehzade Mehmet Türbesi, Üsküdar Mihramah Sultan Camii, Hadım İbrahim Paşa Camii, Süleymaniye Camii kuzey ve batı, Süleymaniye Camii mahfil, Hürrem Sultan Türbesi, Rüstem Paşa Camii, Kanuni Sultan Süleyman Türbesi, Atik Valide Camii, Kadırga Sokullu Mehmet Paşa Camii, Gazi Ahmet Paşa Camii, Piyale Paşa Camii, Selimiye Camii, II. Selim Türbesi, Edirnekapı Mihrimah Sultan Camii kuzey ve batı, Zal Mahmut Paşa Camii, Kılıç Ali Paşa Camii, Siyavuş Paşa Türbesi, Nişancı Mehmet Paşa Camii, III. Murat Türbesi, III. Mehmet Türbesi, Sultan Ahmed Camii Avlu, Sultan Ahmed Türbesi, Yeni Camii, Yeni Camii Hünkâr Kasrı, Hatice Turhan Türbesi kap1 kanatları ile Bursa Yeşil Cami, Edirne Üç Şerefeli Cami, Amasya II. Beyazıt Camii, İstanbul II. Beyazıt Camii, II. Beyazıt Türbesi, Şehzade Mehmet Türbesi, Hürrem Sultan Türbesi (4 pencere kanad1), Rüstem Paşa Camii (2 pencere kanad1), Kanuni Sultan Süleyman Türbesi (4 pencere kanad1), Atik Valide Camii, Kadırga Sokullu Mehmet Paşa Camii, II. Selim Türbesi (5 pencere kanad1), III. Murat Türbesi (3 pencere kanad1), Sultan Ahmed Türbesi pencere kanatları incelenmiştir. Bu 67 kapı ve pencere kanadında 6 kompozisyon 16 kanatta tekrarlanmıştır. Yani 57 kapı ve pencere kanadındaki kompozisyonlar farklı özelliklere sahiptir. Bu kanatlardan Bursa Cem Sultan Türbesi, Fatih Tabhanesi, Tokat Hatuniye Camii, Edirne II. Beyazıt Camii, İstanbul II. Beyazıt Camii, Üsküdar Mihramah Sultan Camii, Hadım İbrahim Paşa Camii, Süleymaniye Camii mahfil, Rüstem Paşa Camii, Atik Valide Camii, Kadırga Sokullu Mehmet Paşa Camii, Piyale Paşa Camii, Zal Mahmut Paşa Camii, Kılıç Ali Paşa Camii, Siyavuş Paşa Türbesi, III. Murat Türbesi, III. Mehmet Türbesi, Yeni Camii Hünkâr Kasrı, Hatice Turhan Türbesi kapı kanatları ile Edirne Üç Şerefeli Cami, Amasya II. Beyazıt Camii, II. Beyazıt Türbesi, Hürrem Sultan Türbesi (3 pencere kanadı), Rüstem Paşa Camii (2 pencere kanad1), Kanuni Sultan Süleyman Türbesi (3 pencere kanadı), Atik 
Valide Camii, Kadırga Sokullu Mehmet Paşa Camii, II. Selim Türbesi (1 pencere kanadi ${ }^{14}$, bu pencere kanadının III. Murat Türbesindeki pencere kanadı ile tamir sırasında değiştirildiği düşünülmektedir), III. Murat Türbesi (2 pencere kanad1) ve Sultan Ahmed Türbesi pencere kanatları $72^{\circ}$ açıya sahip bir dikdörtgen içerisinde tasarlanmışlardır.

Hakem Değerlendirmesi: Dış bağımsız.

Çıkar Çatışması: Yazar çıkar çatışması bildirmemiştir.

Finansal Destek: Yazar bu çalışma için finansal destek almadığını beyan etmiştir.

Peer-review: Externally peer-reviewed.

Conflict of Interest: The author has no conflict of interest to declare.

Grant Support: The author declared that this study has received no financial support.

\section{Kaynakça/References}

Arık, M.,-Sancak, M., Pentapleks Kaplamalar, Tübitak, 2006.

Arık, R.,-Arık, O., Anadolu Toprağının Hazinesi Çini Selçuklu ve Beylikler Çă̆ Çinileri, Kale Grubu Kültür Yayınları, İstanbul, 2007.

A. Mehmet Avunduk, Mimar Sinan'ın İstanbul'daki Camilerinde Ağaç Sanatı, İstanbul Üniversitesi, Sosyal Bilimler Enstitüsü Yayımlanmamış Doktora Tezi, İstanbul, 1996.

Barışta, H. Ö., Osmanlı İmparatorluğu Dönemi İstanbul Camii ve Türbelerinde Ağaç İşleri, AKM, Ankara, 2009.

Baykuşoğlu, S., “A Research on Islamic Geometric Patterns”, 2009, s. 34. http://www.serkanbaykusoglu.com/ ResearchOnIslamicGeometricPatterns.pdf (01.08.2019)

Bozer, R., "Sinan Eserlerinde Ahşap İşçiliğì", VI. Vakıf Haftası, Türk Vakıf Medeniyeti Çerçevesinde "Mimar Sinan ve Dönemi” Sempozyumu (5-11 Aralık 1988, İstanbul), İstanbul, 1989, s. 327-346.

Bozer, R., 15. Yüzyılın Ortasına Kadar Anadolu Türk Sanatında Ahşap Kapılar, Ankara Üniversitesi Sosyal Bilimler Enstitüsü, Yayınlanmamış Doktora Tezi, Ankara. 1992.

Bozer, R., “Ahşap Sanatı”, Anadolu Selçukluları ve Beylikler Dönemi Uygarlığı 2, Kültür ve Turizm Bakanlığı, Ankara, 2006, s. 533.

Bulut, M., Selçuklu Çizgileri Anadolu Selçuklu Geometrik Kompozisyonları, Inkılab Basım Yayım, İstanbul, 2020.

Demiriz, Y., “XIV. Yüzyılda Ağaç İşleri”, Yüzyıllar Boyunca Türk Sanatı (14. Yüzyıl), Haz: Oktay Aslanapa, MEB, Ankara, 1977, s. 61-71.

Doğanay, A., Klasik Devir Osmanlı Hanedan Türbeleri, Klasik Yayınları, İstanbul, 2009.

Döngel, İ., İstanbul'daki Mimar Sinan Eseri Cami Kapılarının İncelenmesi, Gazi Üniversitesi Fen Bilimleri Enstitüsü Yayınlanmamış Yüksek Lisans Tezi, Ankara, 2013.

Ersoy, A., XV. Yüzyıl Osmanlı A ̌̆aç İşçiliği, Marmara Üniversitesi Yayınları, İstanbul, 1993.

Kerametli, C., “Osmanlı Devri Ağaç İşleri Tahta Oyma Sedef Bağ ve Fildişi Kakmalar”, Türk Etnografya Dergisi, S: IV, MEB Eski Eserler ve Müzeler Genel Müdürlüğü, Ankara, 1961, s. 5-13.

14 Aziz Doğanay, Klasik Devir Osmanlı Hanedan Türbeleri, Klasik Yayınları, İstanbul, 2009, s. 296. 
H. Baki Kunter-A. Sami Ülgen, "Fatih Camii”, Vakiflar Dergisi, S. 1, Ankara, 1938.

Ögel, S., “Anadolu Ağaç Oymacılığında Mail Kesim”, Sanal Tarihi Yıllı̆̆g, S: 1, Baha Matbaası, İstanbul, 1965, s. 110-117.

Öney, G., “Anadolu Selçuklu ve Beylikler Devri Ahşap Teknikleri”, Sanat Tarihi Yılll̆ğl, S: 3, Edebiyat Fakültesi Matbaası, İstanbul, 1970, s. 135-150.

Söğütlü, C., vd., "İstanbul'da Bulunan Mimar Sinan Eseri Cami Ahşap Kapı ve Pencere İç Kepenklerinin Malzeme, Boyut, Süsleme ve Yapım Tekniği Açısından İncelenmesi”, Politeknik Dergisi, C: 17, S: 2, Ankara, 2014, s. 49-57.

Yücel, E., "Osmanlı Ağaç İşçiliği”, Kültür ve Sanat, İstanbul, 1977, s. 58-71. 
